\title{
Elementary Schools' Response to Student Wellness Needs During the COVID-19 Shutdown: A Qualitative Exploration Using the R=MC2 Readiness Heuristic
}

Hannah Calvert ( $\sim$ hannahcalvert898@boisestate.edu )

Boise State University https://orcid.org/0000-0002-6067-693X

Hannah G. Lane

Duke University

Michaela McQuilkin

Boise State University

Julianne A. Wenner

Boise State University

Lindsey Turner

Boise State University

\section{Research}

Keywords: Organizational readiness, education, health, capacity, digital divide

Posted Date: February 4th, 2021

DOl: https://doi.org/10.21203/rs.3.rs-165657/v1

License: (9) This work is licensed under a Creative Commons Attribution 4.0 International License. Read Full License

Version of Record: A version of this preprint was published at International Journal of Environmental Research and Public Health on December 27th, 2021. See the published version at https://doi.org/10.3390/ijerph19010279. 


\section{Abstract}

Background: During spring of 2020, the COVID-19 pandemic and accompanying public health advisories forced K-12 schools throughout the United States to suspend in-person instruction. School personnel rapidly transitioned to remote provision of academic instruction and wellness services such as school meals and counseling services. When schools operate under typical circumstances, many factors affect their capacity to provide services to students. The aim of this study was to investigate how schools responded to the transition to remote supports, including assessment of what readiness characteristics schools leveraged or developed to facilitate those transitions.

Methods: Semi-structured interviews were conducted in the spring of 2020, with an interview guide informed by school wellness implementation literature. Personnel $(n=50)$ from 39 urban and rural elementary schools nationwide participated. A team of three coders iteratively analyzed the data. After first-cycle open coding, the readiness $=$ motivation capacity ${ }^{2}\left(R=M C^{2}\right)$ heuristic, developed by Scaccia and colleagues, guided coding to determine themes related to schools' readiness to support student wellness in innovative ways during the pandemic closure. Axial coding was then used to connect codes to themes within each readiness construct.

Results: Two distinct code sets emerged, defined according to the $\mathrm{R}=\mathrm{MC}^{2}$ heuristic (1) Innovations: roles that schools took on during the pandemic response, and (2) Readiness: factors influencing schools' motivation and capacity to carry out those roles. The innovation was defined as a network of support for student wellness, which included themes such as serving meals, providing wellness services, and promoting positivity. Emergent themes related to Readiness included recognizing the need to support disadvantaged families, positive influence of local school leaders in coordinating the network, and attitudes of schools and the surrounding communities to "do anything it takes" to facilitate the network. Technology infrastructure was a cross-cutting theme which impacted schools' readiness to carry out the network of support. Differences emerged between urban and rural schools.

Conclusions: Schools demonstrated unprecedented capacity and motivation to provide crucial wellness support to students and families early in the COVID-19 pandemic. These efforts can inform future resource allocation and new strategies to implement school wellness practices when schools resume normal operations.

\section{Contributions To The Literature}

- Methods demonstrate the applicability of $\mathrm{R}=\mathrm{MC}^{2}$ organizational readiness heuristic to school settings

- Methods additionally illustrate $\mathrm{R}=\mathrm{MC}^{2}$ heuristic applicability in the context of rapid organizational efforts to respond to an unanticipated, evolving global phenomenon

- Results show the importance of organizational capacity for rapid adaptation to service delivery due to unexpected circumstances 
- Findings provide groundwork for further studies exploring the application of the $\mathrm{R}=\mathrm{MC^{2 }}$ heuristic to school-based research, which are currently limited

\section{Introduction}

More than 50 million children and youth attended public elementary and secondary schools in the U.S. in 2019 [1]. For many of those students, including the 22 million who receive school lunch at free or reduced price [2], schools are not just settings for educational services, but also for receiving crucial wellness services. According to the Centers for Disease Control and Prevention (CDC), "Aside from a child's home, no other setting has more influence on a child's health and wellbeing than their school" [3]. By March 25, 2020, all public K-12 school buildings were closed due to COVID-19 [4], and the instrumental roles that schools played in continuing to meet the basic physical health and safety needs of students, families, and communities garnered national attention.

Schools are crucial settings for promoting student health and wellbeing [5-9]. In 2014, CDC and ASCD developed the Whole School, Whole Community, Whole Child (WSCC) to highlight the importance of addressing the multifaceted needs of children and youth to foster optimal learning and development [10]. The model highlights 10 components which facilitate health and academic achievement, including social-emotional support (e.g., counseling and curricula), healthy nutrition (e.g., school meals) and physical activity opportunities (e.g., physical education, recess, classroom activities) [11]. These services foster healthy behaviors and development, as well as academic learning [12-14]. Despite the established value of a whole child approach to learning, the ability of schools to prioritize non-academic outcomes is limited $[15,16]$ due to resource constraints and other challenges when implementing WSCC-related policies and programming [17]. These challenges are particularly prominent for schools serving children in higher-poverty areas or belonging to minoritized racial/ethnic groups, who most need school-based services.

The pandemic exacerbated these needs, widening existing disparities in food insecurity, technology access, and parental support for students [18-21]. The response of school leaders and personnel during the pandemic was not without challenges; however, it also illuminated the strengths of school systems in meeting students' needs. Understanding the factors which underlie school successes in supporting student wellness during COVID-19 can inform the provision of federal, state, and local resources for schools to implement the WSCC model in the future.

\section{Theoretical Framework}

Readiness is recognized as a needed precursor for an organization such as a school to adopt and continue implementing an innovation [22-26]. The $\mathrm{R}=\mathrm{MC}^{2}$ heuristic, proposed by Scaccia and colleagues [27], suggests that an organization's readiness (R) to implement an innovative policy, program, or practice results from the organization's motivation (M) for the change, its general capacity $(C)$, and its innovation- 
specific capacity (C) [27]. In short, readiness is a product of an organization's willingness and ability to put an innovation into place. For this study, the pandemic served as a uniform change agent across all schools. The innovation encompasses each school's unique response to the transition, while operating within the constraints of the federal, state and local context.

Motivation to adopt a new program, practice, or policy relies on the perceived benefits and drawbacks to using said innovation, defined by six factors: relative advantage, compatibility, complexity, trialability, observability, and priority [27]. Although mandated closures meant that most school leaders did not have a choice other than to transition to remote schooling, understanding what motivated school stakeholders' efforts can inform implementation of wellness services in the future.

General capacity is "the context, culture, current infrastructure, and organizational processes at play where an innovation will be introduced" (p. 4, [27]). General capacity (i.e., culture, climate, organizational innovativeness, resource utilization, leadership, structure, and staff capacity) informs whether an organization universally adapts well to change, and does not depend on resources that facilitate a specific innovation [27]. Urban and rural schools' general capacity for wellness initiatives is not wellunderstood. Describing this capacity in the context of a substantial innovation (transitioning to remote provision of services) could be instrumental in informing stronger, more specific recommendations for implementation of wellness initiatives in schools.

Innovation-specific capacity refers to the resources (e.g., financial, tangible) and human capital needed to successfully implement a particular intervention. Activities for building specific capacity are distinct, but can vary in complexity based on the innovation being implemented. During COVID-19, schools' ability to leverage new and existing resources, knowledge, and relationships were likely critical for providing services, and could yield sustained capacity for in-school supports over time. Factors affecting innovation-specific capacity include innovation-specific knowledge, skills, and abilities; having a program champion; specific implementation climate supports; and interorganizational relationships.

\section{Purpose}

This qualitative phenomenological study-conducted in the months after schools initially closed due to the COVID-19 pandemic-explores schools' innovative solutions to provide health and wellness support to students. Through the voices of 50 staff members at 39 elementary schools, we describe how schools adapted services for students and families while prioritizing community safety. We use the $\mathrm{R}=\mathrm{MC}^{2}$ heuristic to define innovations and describe themes related to schools' motivation and capacities for implementation.

\section{Methods}

This study is part of a broader explanatory sequential mixed methods study [28] examining the implementation of wellness practices in elementary schools across the United States. The study had two 
phases: 1) a nationally representative survey, and 2) follow-up semi-structured interviews with survey participants recruited through stratified sampling and snowball sampling. The current analyses focus on interview questions related to schools' transition to remote provision of services in response to COVID-19. Interviews were conducted between April and June 2020.

\section{Sampling And Recruitment}

Demographic information for the 556 schools in the survey sample was obtained from the National Center for Education Statistics (NCES) Common Core of Data [1], including locale, which was used to stratify the sample into rural and urban schools for interview recruitment. Urban and rural schools were selected because they are often attended by students living in high-poverty areas or belonging to a racial/ethnic minoritized group. Emails were sent to 153 personnel from rural schools, and 110 from urban schools. Snowball sampling was employed by asking initial participants to provide contact information for additional staff who might like to participate. All participants received a $\$ 50$ e-gift card.

\section{Data Collection}

Participants. Fifty school personnel (hereafter: "participants") from 39 schools consented to interviews, including 11 referred via snowball. All U.S. regions were represented. School and participant characteristics are listed in Table 1. 
Table 1

Characteristics of public elementary schools and interview participants

\begin{tabular}{|c|c|c|}
\hline Variable & Number & $\%$ \\
\hline \multicolumn{3}{|c|}{ School Characteristics $(n=39)$} \\
\hline \multicolumn{3}{|l|}{ Student race/ethnicity } \\
\hline$\geq 50 \%$ Asian & 1 & 2.6 \\
\hline$\geq 50 \%$ Black & 3 & 7.7 \\
\hline$\geq 50 \%$ Hispanic & 5 & 12.8 \\
\hline$\geq 50 \%$ White & 19 & 48.7 \\
\hline Other & 11 & 28.2 \\
\hline \multicolumn{3}{|c|}{ Socioeconomic status (\% of students eligible for free/reduced-priced meals) } \\
\hline Higher $(<33 \%)$ & 8 & 20.5 \\
\hline Middle $(\geq 33 \%$ to $<66 \%)$ & 16 & 41.0 \\
\hline Lower $(\geq 66 \%)$ & 12 & 30.8 \\
\hline Not reported & 3 & 7.7 \\
\hline \multicolumn{3}{|l|}{ School locale } \\
\hline City: Large & 6 & 15.4 \\
\hline City: Mid-size & 4 & 10.3 \\
\hline City: Small & 9 & 23.1 \\
\hline Rural: Fringe & 9 & 23.1 \\
\hline Rural: Distant & 9 & 23.1 \\
\hline Rural: Remote & 2 & 5.0 \\
\hline \multicolumn{3}{|c|}{ School size (number of students enrolled) } \\
\hline$>650$ & 9 & 23.1 \\
\hline 450 to 649 & 9 & 23.1 \\
\hline 250 to 449 & 12 & 30.7 \\
\hline$<249$ & 9 & 23.1 \\
\hline \multicolumn{3}{|l|}{ Region } \\
\hline West & 8 & 20.5 \\
\hline Midwest & 10 & 25.7 \\
\hline
\end{tabular}




\begin{tabular}{|llc|}
\hline Variable & Number & $\%$ \\
\hline South & 13 & 33.3 \\
\hline Northeast & 8 & 20.5 \\
\hline Interview Participant Characteristics $(\mathbf{n}=\mathbf{5 0})$ & & \\
\hline Role at School & 20 & 40.0 \\
\hline Administrator (Principal/Assistant Principal/Head of School) & 9 & 18.0 \\
\hline Physical Education Teacher & 2 & 4.0 \\
\hline Classroom Teacher & 3 & 6.0 \\
\hline Counselor & 2 & 4.0 \\
\hline Nurse & 7 & 14.0 \\
\hline Administrative Assistant/Office Manager & 7 & 14.0 \\
\hline Other & & \\
\hline Gender (self-reported) & & 80.0 \\
\hline Female & 40 & 20.0 \\
\hline Male & 10 & \\
\hline
\end{tabular}

Instrumentation. The interview guide was initially developed to align with the survey and further explore implementation of wellness practices; it was then adapted to explore participants' perceptions of their role and their school's role in wellness promotion in the context of COVID-19. The final guide included three topics: (1) schools' ongoing COVID-19 response; (2) wellness initiatives in the prior school year; (3) future wellness needs and priorities as children return to school. This analysis reflects the first topic (see Additional File 1 for interview guide questions).

Given the unprecedented situation and timing of interviews while schools were transitioning to-or continuing and adjusting to-online learning, the guide did not reflect a particular framework; rather, it inquired about participants roles in their school's COVID-19 pandemic response, with the question "What roles has your school played in the community to support student health and safety as a result of the pandemic?," followed by probes for details on school meal distribution, and follow-up questions regarding schools' motivation, preparedness, leadership involvement, and resources to fulfill these roles.

Interview Procedures. Interviews were conducted via Zoom or phone call by a single, trained interviewer. Following the interview, the interviewer documented contextual information and captured initial observations $[29,30]$. Interviews were audio recorded via Zoom and transcribed verbatim. Interviews ranged from 19 to 91 minutes (average $=42, S D=13$ ). 


\section{Coding And Analysis}

De-identified transcripts were coded and analyzed using Dedoose Version 7.0.23 (SocioCultural Research Consultants, LLC, 2016). We conducted analysis over two iterative cycles, following best practices for qualitative implementation research and qualitative descriptive design [31, 32]. Our first cycle used open coding, applying codes iteratively to identify a compatible, practical coding structure. Transcripts were first divided into excerpts by question. Subsequently, three coders independently reviewed excerpts across a subset of transcripts to develop an axial coding structure, using memos to document coding decisions as well as emerging patterns within and across questions [30]. Coders met repeatedly to discuss these subsets, including areas of overlap between questions and modifications to code definitions. First cycle coding revealed two separate sets of codes: (1) description of innovative roles schools took on during the pandemic response, and (2) factors that influenced schools' ability to take on and maintain those roles. These findings, as well as our understanding of schools as complex organizations, informed the use of the $\mathrm{R}=\mathrm{MC}^{2}$ heuristic for our second cycle. We adapted our codebook to include relevant constructs described by Scaccia and colleagues, iteratively modifying definitions for innovation, motivation, and general and innovation-specific capacity to be school-specific [27]. Once a stable set of code definitions emerged (see Table 2) and coders demonstrated consistency on $20 \%$ of transcripts, a single coder applied readiness codes to each excerpt, a second coder double-checked a subset of excerpts, and all three coders met as disagreements emerged. To capture themes within constructs and compare across rural and urban schools, we used extensive memo-ing, memo-linking, and team debriefs. Data saturation was reached and no additional sampling was needed. A detailed audit trail was kept throughout the coding process (available upon request).

\section{Results}

We present our findings in two sections: First, we define the innovative approach of schools to meet students' academic and wellness needs. Second, we describe components of schools' readiness for innovative approaches, including themes related to motivation, general capacity, and innovation-specific capacity.

\section{Innovation: A "network of support"}

Participants described many important non-academic roles of schools in protecting the health and safety of students during COVID-19, which we conceptualize as a "network of support" (Figure 1). Schools leveraged technology not only to support academics, but also to continue and expand wellness-related services provided during the school year.

[Figure 1 Caption] Bubbles with darker shading reflect a higher frequency of mentions by participants.

In addition to providing support for virtual learning through distribution of laptops, Wi-Fi hotspots, learning packets and use of learning management platforms, the four most-frequent components of 
schools' network of support included:

Serving Meals. Meal service occurred in nearly every school district, but varied in scope and approach. Participants described innovative pick-up and/or delivery models for serving nutritious meals to students, especially those with the highest need, including grab ' $n$ ' go meal pickup or delivery to neighborhoods and homes using school busses.

Providing Wellness Resources. Schools provided information and resources to help keep families safe from COVID-19 as well as staying physically, mentally, and emotionally well. Resources were distributed on the same platforms as virtual learning. A community assistance staff member at an urban school shared, "The school has developed a virtual wellness center. They gathered videos with music, guided reflections, visual relaxations, yoga...exercises and mindful videos."

"A place to feel connected." Participants described methods they used to maintain contact with students and families. This mostly occurred via instructional platforms, with follow-up home visits when students could not be reached via web or phone. Participants felt that maintaining this connection was invaluable to students and families. A counselor at a rural school noted, "Reaching out to families made all the difference in the world. A lot of parents said, 'Thank you for just checking on us."'

Promoting Positivity. Participants tried to maintain schools' role as a place of positivity, consistency, and pride for both students and staff. Examples included birthday car parades, daily motivational social media posts or individual messages, and school decorations:

We met individually via Zoom with every staff member, [to tell] them what we appreciate about them. I've never seen more tears. People are really being reminded of why they do what they do and how gratifying a profession it is. And I got so many comments back like 'This was so much better than getting a gift card to a restaurant' -Urban Principal

Other components of the network of support included providing mental health support through virtual counseling, providing technology support, and providing tangible resources (e.g., gift cards, offering to go grocery shopping).

\section{Readiness}

While being "ready" for a crisis of the magnitude of COVID-19 was unlikely, schools described various factors that provided motivation (i.e., commitment or drive to implement innovation) for their network of support, as well as existing or quickly-built capacity to carry it out.

\section{Motivation}

School stakeholders' motivation to carry out their version of a network of support fell overwhelmingly into three R $=\mathrm{MC}^{2}$ constructs: Simplicity/Compatibility, Priority, and Observability. Codebook definitions and themes for each construct and provided in Table 2. Due to space limitations, not all themes appear in the 
text, but all appear in Table 2. A sampling of notable quotes for each construct are provided in Additional File 2. 
Table 2. Codebook Definitions and Themes for Schools' Readiness to Implement a Wellness Network of Support

\section{$\mathrm{R}=\mathrm{MC}^{2}$ Construct and Theme(s) \\ Definition}

\section{Motivation/Momentum}

Features of an innovation that contribute to whether people want to do it and commit to making it happen

\section{Simplicity and Compatibility*}

Extent to which network was perceived as an easy role for schools to fill or within the way school usually does things

\section{Priority}

Importance of network of support compared to academics

\section{Observability}

Ability to see or foresee that providing a network of support was what families needed during COVID
Theme 1: Schools are often the hub of communities/strategic distribution points for resources

Theme 2: Pre-existing services were not difficult to adapt or maintain for COVID-19 delivery
Ability to Pilot
Few excerpts emerged; no themes were identified

Degree to which network can be tested or experimented with

Theme 1: State mandates required schools to provide meals to students

Theme 2: School personnel went above and beyond to extend meal services to the whole community out of desire to meet basic needs

\section{General Capacity}

Characteristics or conditions applicable for any innovation within an organization

Process Capacities

Ability to plan, implement and evaluate efforts to meet student needs
Theme 1: Student participation rates in existing programs such as free/reduced price meals made the need for a network of support clear

Theme 2: Personnel from smaller schools described greater ease in identifying which families had the greatest need 
Theme 4: Schools used many informal methods to monitor/adjust the network to better meet student needs, including extensive communication with parents

Theme 5: Schools used many informal methods to monitor/adjust the network to improve operations or logistics and reduce virus spread

\section{Resource Utilization}

Ability to use existing funds or technological resources to create infrastructure for student wellness

\section{Staff Capacities}

Having enough staff who can to take on any role to meet student needs
Theme 1: Technology was the most critical resource for supporting students during COVID-19; distribution of laptops and/or hotspots was a high priority

Theme 2: Some technology barriers could not be overcome, and schools instead delivered hardcover textbooks, flash drives or paper packets via bus.

Theme 3: Having learning management systems (e.g., Google Classroom, Class Dojo) and more tech-trained staff were advantages

Theme 1: Many staff members took on new roles to keep operations going, minimize number of staff in the building, and remain employed

Theme 2: Staff primarily pivoted to helping with meal service

Theme 3: Some staff described new roles: calling students who were not attending class; bilingual staff aiding non-English-speaking parents; connecting students to community resources; providing technical support

Theme 1: School closures necessitated new methods of communication among staff

Theme 2: Teamwork and resource-sharing were essential and occurred naturally; staff members teamed up in new ways to achieve their goals

Theme 3: Caregivers served a key new role in operating the network; communication with families was essential, but challenging

Theme 1: Local leadership was perceived very positively, views of non-local leadership (state/federal) were mixed

Effectiveness of school and district leaders
Theme 2: Positive leadership actions often overlapped with themes related to internal operations and process capacities, including: (1) being attentive and in frequent contact, sharing decision-making without creating "decision fatigue" among staff (2) providing emotional support for staff and students, including "trusting" teachers and keeping expectations realistic

Theme 3: Leadership were influential in ensuring students had the supplies and resources they needed

\section{Innovation-Specific Capacity}

Characteristics or conditions necessary to implement specific innovations within an organization

Knowledge \& Skills

Ability of staff to create network of support for students

Program Champion

Specific people within the school who are
Theme 1: Staff had base knowledge, but still experienced a learning curve

Theme 2: As noted in internal operations, parents become key parts of organization who also needed knowledge and skills to facilitate student success; lack of parent knowledge was a barrier

Theme 1: While teamwork was often noted, sometimes individuals who excelled in filling new/existing roles were mentioned as leaders 


\section{Supportive Climate}

Staff attitudes, parent attitudes, and examples of culture, norms or values that facilitate network

\section{Inter-organizational Relationships}

Support for network from other schools, community partners, volunteers, other external organizations

\section{Intra-organizational} Relationships

\section{Relationships}

between

administrators, staff

and families to

support network
Theme 1: Staff were willing to do "whatever it takes" to support families, many spoke that taking care of each other was part of the school culture

Theme 2: Meeting basic needs was a primary concern of school staff, rather than over-emphasizing academics

Theme 1: Most schools relied on local food banks, churches, state agencies, internet companies, and other organizations to help meet student needs

Theme 2: Teachers and administrators worked across districts to collaborate and share resources

Theme 3: Teachers utilized online networks to adapt their instruction and transition to virtual platforms

Intra-organizational relationships had extensive overlap with process capacities/internal operations; few unique excerpts emerged; no additional themes were identified

Note: Constructs of Relative Advantage and Innovativeness were not assessed due to the pandemic forcing decision-making regarding adoption. Additionally, Simplicity and Compatibility constructs were combined into one construct, and all Culture and Climate constructs were combined into one construct.

Simplicity and Compatibility. Many personnel described their schools as being community "hubs" prior to COVID-19, where resources and services (including meals), social-emotional support, and counseling, are provided. Thus, schools reported motivation to continue serving as this hub and offering services, adapting delivery models to adhere to their local government's social distancing guidance.

Schools' existing partnerships with community organizations (e.g., food banks, mental health providers, churches) made it simpler to step into their new role, as they had previously identified student needs and secured resources to create their network of support. As noted by a physical education teacher at a rural school: "Our community has always been this way. [When] there's any kind of disaster... we just have these certain organizations in place that...reach out to help the community."

Priority. In terms of serving meals during COVID-19, schools were motivated not only by legal obligations, but a strong moral obligation to offer meals and, in some cases, extend meal programs to non-school aged children, parents, or any individual in need. Regardless of network components, participants acknowledged schools' imperative to prioritize students' basic wellness needs, which must be met before they can learn. This was summed up by an urban principal, who stated, "One thing we know is that kids 
can't learn if they're not fed, and not just fed food, but fed emotionally, fed from a security standpoint. That's why we have tried make things as normal as possible."

Observability. Participants knew that their students' families would need support, and often described being motivated by the needs of their communities. Many created plans to reach individual students whom they knew would have limited or no access to the network of support (e.g., printing learning packets, providing hotspots for students without Internet access, routing busses to deliver meals to families with transportation barriers).

\section{Capacity (General)}

General capacity (attributes of functioning schools) constructs that influenced schools' abilities to provide the network of support included: process capacities, resource utilization, staff capacities, internal operations, and leadership.

Process Capacities. There was little preparedness, planning, or formal evaluation of the network of support throughout COVID-19 school closures, but schools quickly took action without hesitation:

Schools are general very reticent to change, but [we] really had to adapt quickly...If something didn't work, we brainstormed that day, and tried something new the next day. We were not prepared at all, [but we] became prepared. When it's all over, I think we'll look back and go, 'wow, we can pat ourselves on the back.' There's a lot to be proud of. - Urban Principal

Participants described factors that supported or hindered their initial actions. Factors that supported initiation of the network included: having existing infrastructure (e.g., technological systems, staff, programs), team decision-making, hands-on leadership, and lessons learned from other schools/districts. Hindering factors included a lack of existing infrastructure and constant decision changes and/or slow decision-making by state or local leaders.

Schools used a variety of informal methods to monitor and adjust their processes, including constant communication with families through broad surveys and individual calls/emails/home visits, and observing bus routes. There were frequent changes, particularly in meal service processes, intended to either better reach students (e.g., expanding bus delivery route or locating new sites near public transportation stops) or improve operations and prevent virus spread (e.g., reducing routes, serving multiple meals/day on fewer days).

Resource Utilization. Technology was the most critical resource for the network of support. Helping families overcome anticipated technology barriers was a high priority during the initial weeks of closures, including distributing laptops and/or hotspots to families, setting up parking lot hotspots, and providing technical support to families. Despite these efforts, several participants noted that some students were simply unable to be reached due to limited cell service or low digital literacy. Learning management platforms (e.g., Google Classroom, Class Dojo) were also key resources. Some schools already had these platforms in place, whereas others had to purchase and/or learn to use them. Beyond technology, another 
resource advantage was existing infrastructure that could be adapted or expanded, rather than started from scratch, such as backpack programs, counseling services, and food and staffing for meal service. As a secretary at a rural school noted, "Because we already had that [backpack] program going, it was just a matter of replenishing those cupboards. Other than that, it's been pretty smooth." Participants also described the broad availability of resources from other organizations and districts around the country due to the universality of school closures.

Staff Capacities. Many staff members such as teaching assistants, transportation and administration staff, and other non-classroom teachers "stepped up to the plate," taking on new roles to keep operations going. Staff primarily pivoted to helping with meal preparation and distribution, ensuring that those programs were well-supported. Additional roles included identifying and connecting students to community resources and providing technical support. These new roles kept staff employed, but also enabled more access to students and a better understanding of schools' non-academic role.

People always take very seriously the academic part of our mission, but I'm not sure that staff are so focused on how kids are feeling, what they're going through, what their home life looks like. That gets compartmentalized, so the school nurse, the school counselor, or school psychologist, they worry about those things, and everybody else does their job. In this situation, we've gotten a much broader view of our jobs. Our [Spanish and art] teachers have gotten much more involved in finding out what's happening with kids at home.

- Urban Principal

Internal Operations. While remote methods of communication among staff and between leadership and staff were not ideal, communication was critical, particularly in the early weeks of school closures, as decisions changed quickly and information needed to be shared expediently.

Participants reported the importance of teamwork to develop meal distribution protocols, plan lessons, and identify students who needed additional support. Participants described forming new teams to solve new problems, such as nurses and cafeteria staff developing contact-free meal pick-up protocols, classroom and specials teachers integrating lesson plans, and technology teachers supporting other staff members with virtual platforms.

By necessity, families became essential members of the school's internal operations, and while schools increased their communication with parents, the expectation of "parents as partners" was not always realistic due to various barriers, such as language barriers, work schedules, lack of internet, frequent mobility and changing phone numbers. Staff members relied on teamwork to reach out to parents, employing both broad (e.g., RoboCalls, surveys) and individualized (e.g., targeted calls or visits to families who had not engaged) strategies. As an urban principal observed, "It's a big team effort to keep up with kids who aren't participating. There's a team that meets every week, we talk about those kids who haven't been able to participate to any degree. We just want to make sure they're safe, we want them to participate." 
Leadership. Perceptions of leadership varied among participants. Local leaders (e.g., principals, food service directors, superintendents) were perceived positively, while there were mixed opinions about nonlocal leadership. Problems arose when leaders were less present or involved, constantly changed decisions, or had inadequate communication with staff. A principal at a rural school summarized, "The district did a great job providing what was needed on the ground. I feel like the state and federal guidance and clarification and funding were, um, unclear at best."

Positive leadership actions overlapped with process capacity and internal operations themes, including swift communication about decisions, involving staff in decision-making, and sharing resources as they became available. Leaders also provided emotional support and stability for staff and students. As a principal at an urban school noted, "[I'm] trying to be the liaison between the changing state directives and the district directives and then getting them out to our teachers in a way that doesn't overwhelm them. I'd say the biggest thing is just being a cheerleader." Participants frequently described the ways in which leaders went "above and beyond" to meet students' needs, such as purchasing learning platforms that were appropriate for young children, calling families to notify them of meal distribution route changes, and facilitating district-wide technology trainings for staff.

\section{Capacity (Innovation-Specific)}

Innovation-specific capacity-attributes of schools that facilitate adopting an innovation-affected the network of support, with constructs including: knowledge and skills; having a program champion; a supportive climate; and inter-organizational relationships.

Knowledge and Skills. In terms of novel skills and knowledge, technical expertise was critical. Participants felt more prepared for the transition to remote services if their schools had access to an information technology department or specialized technology staff. In the absence of this department, schools relied on staff who happened to be tech-savvy. Some larger districts described advantages, as reflected by a principal at an urban school:

We're very fortunate...that we have a technology director who also has a staff of technology integrationists, and every elementary building has a media specialist. All of those people have expertise in distance learning, and were able to problem solve 99 percent of the problems that we've run into.

However, the effect of technology knowledge was two-fold; not only did staff in many instances need to learn new strategies on the fly, but many parents struggled to support their younger children with learning technologies. A participant whose school role was as a Learning Director in an urban school noted, "[Many parents] didn't know how to turn on and off the iPad versus the Chromebook or help their kid get on the camera... or even put in the Wi-Fi."

Program Champion. Participants described specific staff members who exceeded expectations of their traditional role. When a staff member was a champion for families, often they were described as engaging in activities such as personally running errands to get families food, travelling to students' 
homes to provide resources and reassurance, or advocating on their behalf to secure internet access. Some also used social media in innovative ways to keep up morale and engagement, instead of or in addition to being a physical presence. Information technology staff, or others who helped with the digital transition, were often mentioned for being invaluable to meeting student/staff needs and dedicating extra time.

Supportive Climate. Supportive climate reflected aspects of staff and community attitudes and culture that affected the network of support. The attitudes toward the network of support emphasized the drive of school administrators, staff, and surrounding communities to band together and do anything necessary to support families, much like first responders in a crisis. A physical education teacher at a rural school noted, "It seems like our school just jumps in when there's someone [that] needs help. They don't see a barrier. They just go." Another theme that facilitated the network was "giving grace" to parents who were frustrated and overwhelmed with the new realities of pandemic. School staff understood the difficulty of the situation and made sure they were showing support and not over-emphasizing academic expectations. Leaders noted that they were primarily concerned with taking care of their staff's mental wellbeing, as well as making sure families had everything that they needed to function-most commonly including meals and technology support.

Inter-organizational Relationships. Schools mentioned relying on outside assistance to ensure students and families had access to meals in addition to school meals programs. Numerous organizations were noted as integral to mobilizing meal distribution for families, including local food banks, non-profits, faith-based organizations, restaurants, and food service contractors.

A second relationship that emerged was between schools and internet providers; with household internet access becoming critical for schools to reach students, ensuring internet access for everyone became a mission. Some schools struggled with this relationship while other schools had more success brokering deals with the internet providers for families most in need.

\section{Differences Between Rural/Urban Schools}

Though all schools had similar innovations in terms of the network of support, some differences in implementation strategies between urban and rural schools were apparent. Urban schools had greater ease getting resources to students, while rural schools had to rely on creative strategies to access students living in distant areas. Although rural school staff tended to see their small size as an advantage, this paired with relying on a greater network of partnerships within their community to "get everyone what they needed." See Table $\mathbf{3}$ for a contrast of emergent themes that varied across urban and rural schools.

Table 3. Contrasting Themes between Rural and Urban Schools for Capacity Constructs 


\section{Theme(s)}

Theme 1: Being a "small" school or in a small district was often viewed by rural personnel to be advantageous during the COVID-19 response. Being small meant having (1) fewer technology and food resources to distribute, (2) more knowledge of individual student/family situations and needs; and (3) a more tightknit staff and communication network. Rural personnel also described the importance of their role as a "hub" of the community.

\section{Representative Quote(s)}

"Luckily we're a smaller school, smaller staff. We all work well together anyways. So I think that was a positive for us." -Rural Physical Education Teacher

"We're kind of a small, small community. So most people just go straight to the boss and they ask the questions and they get the answers they need." - Rural Principal

"Every student received at least a Chromebook if not an iPad, or both, and um laptops for the older kids. So everyone got something...So because we're so small, I think it was a little bit easier for us to take this on...we're mighty because we're small."

-Rural Principal

Theme 2: Both urban and rural schools faced technology-related barriers, but rural personnel described unique barriers; (e.g., children lived in more remote areas where the distribution of hotspots was not possible). Rural personnel described innovative mitigation strategies, but noted that for some families, the digital divide could not be overcome and they could not be integrated into the network of support.
"I only have one student that's getting online with me and my team teachers only have 4 students out of our 27. So we're copying out lesson plans that we're making. And they're being placed at the little grocery store that's in the nearby town, and parents are asked to go to that grocery store and pick up the lesson plans for their students." - Rural Classroom Teacher

"We do have some resources that we put out on Facebook and the web page for activity ideas and things like that to go along with their lessons, but we're very rural, and we're very spread out. So we have a lot of students who don't have access to internet actually." - Rural Secretary

Theme 3: Rural schools depended on a larger network of community partnerships and support (including faith-based and other community organizations and parent volunteers) to meet the needs of students/families, while urban school participants were more likely to describe how school staff came together to meet the needs of students/families.
"One of my volunteers that attends the local Christian church stepped up, talked with her minister, and we did some of the packing of the bags in the church basement. So this has been a blessing...we have excellent community, and they are such caring people." -Rural School Nurse

\section{Discussion}

Our study describes the critical roles rural and urban schools played in supporting student wellness, and the infrastructure and processes that supported these roles during the COVID-19 pandemic. It is 
unrealistic to think that any school could have been fully prepared for the abrupt transition to a completely remote provision of services; nevertheless, schools did not hesitate to take on these roles. We applied a well-established organizational readiness heuristic to understand what helped and hindered implementation of a network of support for students and families during the pandemic.

Our study indicated that the biggest motivators for schools to provide non-academic services during COVID-19 included simplicity and/or compatibility with existing services and observability, or doing what was "morally right," making sure students were fed and that families and school staff knew that they were cared for. These efforts were recognized and appreciated by families and staff. In another exploration of COVID-19 school meal delivery, food service directors noted a similar potential "silver lining" of the pandemic: that parents' increased exposure to school meals allowed them the opportunity to see that meals are more nutritious than previously thought [33]. Our findings support prior studies that also demonstrated the strength of alignment of wellness efforts with the school stakeholders' motivation for taking on new roles $[34,35]$.

In terms of general capacity, our study is not the only one to bring attention to what one rural principal referred to as the "elephant in the room moving forward;" that is, the digital divide that prohibited students with limited or no technology access from benefiting from schools' network of support during COVID-19, particularly among rural schools [36, 37]. While schools' creative solutions described by participants in our study may have been able to minimize this disparity short-term, it is unclear whether these solutions will be sustainable or sufficient to overcome persisting factors such as home access to Wi-Fi, students having minimal supervision or parents having limited technology skills, and exacerbated economic challenges. Even as face-to-face school has partially resumed, the digital divide continues to put some children behind, and while technology infrastructure was clearly beneficial for schools' efforts to reach students, schools cannot take on the sole responsibility of filling this gap.

A common theme within process capacities and internal operations was that having established channels of communication for both staff and parents gave schools an advantage. The frequent changes in school operations during COVID-19 necessitated constant communication with parents, and parental receptivity to this communication was viewed as an even more critical factor for student wellbeing during the pandemic closure than pre-pandemic. This is consistent with work showing that parent engagement is crucial for many school initiatives, including wellness-related efforts [38]. Future implementation efforts in urban and rural schools should build upon the progress made in engaging parents necessitated by the COVID-19 crisis.

Within innovation-specific capacity constructs, knowledge and skills, emergent program champions, supportive climate, and external partnerships were all key factors supporting schools' readiness. While most schools had no shortage of willingness to help students and families, the capacity that schools could use-existing knowledge, resources, and partnerships-for additional support made a big difference in their success. Innovation-specific capacities built for this remote provision of services, such as tracking systems for flagging kids in need of support, and building parents' skills for navigating digital 
communication, could be leveraged to meet needs of hard-to-reach students in the future. Themes related to both general and innovation-specific capacity underscored a consistent finding in school-based implementation research: the overlapping presence of strong leadership, staff champions, resources, and a supportive climate is essential for successfully implementing school-based wellness initiatives [35, 3842].

When we contrasted emerging themes for rural and urban schools, only a few differences emerged. These primarily related to differing technology barriers and the advantages/disadvantages of being a small or large school. Few studies have qualitatively explored implementation of wellness practices across school locales, but some have shown that rural schools with successful wellness practices rely on larger networks of community resources to provide wellness services [43, 44]. When developing implementation supports for schools, it is important to consider the unique challenges and strengths of urban and rural schools.

While school health advocates and researchers have been promoting the CDC's WSCC approach for years, an important finding of this study was the recognition of its importance by school stakeholders, parents, and community members. Participants often reinforced the notion that "school is much more to kids than just a place to learn." In particular, the acknowledgement that meeting students' mental and emotional health needs was a key purpose of the network of support, was striking. As was further brought to light by the events of 2020, trauma-informed practices, including recognizing the role inequities among racial/ethnic minorities and socioeconomically disadvantaged children play in perpetuating health and educational disparities, warrant serious and sustained attention in school communities [45].

The pandemic has clearly changed schools' approach to meeting students' health and wellness needs, with an emphasized focus on supporting the whole child. However, it remains unclear whether schools will have the capacity to sustain or expand those roles long-term. For example, flexible distribution of school meals may be advantageous for increasing meal access in the long run, however, revenue shortfalls from these programs in the first months of pandemic-related school closures [46] suggest that this mode of operation is not sustainable without alternating current school meal reimbursement structures. A recent report described the COVID-19-related closures as a key inflection point for public schools, with the rising public recognition, innovative use of technology, and "new allies" in communities and among parents [47]. As noted by school personnel in this study, many opportunities exist for leveraging newly created infrastructure to improve implementation of school wellness initiatives longterm.

\section{Limitations}

Our study has several limitations. First, the six sub-categories of rural and urban locales were not equally represented, and only two schools from remote rural regions participated; thus, conclusions about the specific constraints of schools in geographically remote areas could not be fully explored. Second, our 
investigation did not explicitly apply an equity lens to understand how upstream factors (e.g., hiring practices, segregation, racist policies) influenced schools' readiness during the pandemic, and hinder/enable capacity post-pandemic $[48,49]$. These factors should be the focus of future research.

\section{Conclusions And Future Directions For Research}

While our study provides critical insights from school personnel during the early stages of pandemic response, continuing to conduct rigorous mixed-methods implementation research to understand schools' organizational climate for implementing the WSCC model as school operations continue amidst COVID-19, is imperative. Despite frequent discussion of readiness as a pre-implementation factor, Wandersman and colleagues describe readiness as dynamic, positing that capacity and motivation "rise and fall over time" [50]. The extent to which COVID-19 school closures have contributed to the "rise" in schools' readiness to adopt or continue wellness innovations, should be empirically investigated. Our application of the $\mathrm{R}=\mathrm{MC}^{2}$ heuristic as a theoretical lens should can be expanded upon in accordance with other research [51], in order to further operationalize organizational readiness for wellness policies and practices in under-resourced schools. Specifically, exploring which readiness constructs are most crucial for improving adoption and implementation of whole child wellness interventions could inform tailored and equitable implementation supports for rural and urban schools (see [46, 52]).

Findings highlight the heroic response of schools to the unprecedented disruption and devastation of the COVID-19 pandemic. School leaders and staff were motivated by a moral imperative to support students and their communities. However, institutional capacity was needed in order to make the rapid pivot needed to provide critical resources, such as food and internet access, to students. Increasing tangible support and resources (e.g., funding) can ensure that the nation's public education system provides a network of support to students at all times, not only during times of crisis. As schools face an uphill battle to address inequities exacerbated by COVID-19, the current moment is critical for decision-makers to advocate for additional resources for continued implementation and sustainability of WSCC-aligned efforts.

\section{Declarations}

\section{Ethics approval and consent to participate}

This research was approved by the Institutional Review Board at Boise State University, protocol number 101-SB19-151, and all participants provided written consent for the interviews.

\section{Consent for publication}

Not applicable.

\section{Availability of data and materials}


The individual transcripts analyzed during the current study are not publicly available, but a detailed audit trail of the analysis process is available from the corresponding author on request.

\section{Competing interests}

The authors declare that they have no competing interests

\section{Funding}

This study was funded through a grant from Robert Wood Johnson Foundation's Healthy Eating Research (\#76291). Robert Wood Johnson Foundation/Healthy Eating Research had no role in the study design, data collection, analysis, interpretation, or writing of the manuscript.

\section{Authors' contributions}

$\mathrm{HC}, \mathrm{HL}, \mathrm{MM}, \mathrm{JW}$, and LT conceptualized the research design. MM conducted the data collection process. $\mathrm{HC}, \mathrm{HL}$, and $\mathrm{MM}$ analyzed and interpreted the data and drafted the manuscript. JW and LT provided substantial revisions to the manuscript. All authors approved of the final submitted manuscript.

\section{Acknowledgements}

Not applicable.

\section{Author's Information}

MM holds a Master's in Social Work. $\mathrm{HC}, \mathrm{HL}$, and $\mathrm{LT}$ have extensive experience working with schools to implement wellness interventions. JW previously worked in K-12 education and has broad expertise in qualitative research. LT is the Director of the Center for School and Community Partnerships at Boise State University.

\section{References}

1. United States Department of Education. National Center for Education Statistics Common. Core of Data. https://nces.ed.gov/ccd/.

2. United States Department of Agriculture Economic Research Service. National School Lunch Program. https://www.ers.usda.gov/topics/food-nutrition-assistance/child-nutritionprograms/national-school-lunch-program/.

3. Centers for Disease Control and Prevention. School decision-making tool for parents, caregivers, and guardians. 2020. https://www.cdc.gov/coronavirus/2019-ncov/community/schoolschildcare/decision-tool.html.

4. The Coronavirus Spring. The historic closing of U.S. schools (a timeline). Education Week. 2020. https://www.edweek.org/leadership/the-coronavirus-spring-the-historic-closing-of-u-s-schools-atimeline/2020/07. 
5. von Hippel PT, Workman J. From kindergarten through second grade, U.S. children's obesity prevalence grows only during summer vacations. Obes Silver Spring Md. 2016;24(11):2296-300.

6. Story M, Nanney MS, Schwartz MB. Schools and obesity prevention: creating school environments and policies to promote healthy eating and physical activity. Milbank Q. 2009;87(1):71-100.

7. Moreno JP, Johnston CA, Chen T-A, O'Connor TA, Hughes SO, Baranowski J, et al. Seasonal variability in weight change during elementary school. Obes Silver Spring Md. 2015;23(2):422-28.

8. Nord M, Romig K. Hunger in the summer. J Child Poverty. 2006;12(2):141-58.

9. Weaver RG, Armstrong B, Hunt E, Beets MW, Brazendale K, Dugger R, et al. The impact of summer vacation on children's obesogenic behaviors and body mass index: a natural experiment. Int J Behav Nutr Phys Act. 2020;17(1):153.

10. Lewallen TC, Hunt H, Potts-Datema W, Zaza S, Giles W. The Whole School, Whole Community, Whole Child Model: a new approach for improving educational attainment and healthy development for students. J Sch Health. 2015;85(11):729-39.

11. Centers for Disease Control and Prevention. Results from the School Health Policies and Practices Study 2014. 2015. https://www.cdc.gov/healthyyouth/data/ shpps/pdf/shpps-508final_101315.pdf.

12. Michael SL, Merlo CL, Basch CE, Wentzel KR, Wechsler H. Critical connections: health and academics. J Sch Health. 2015;85(11):740-58.

13. Schwartz $A E$, Rothbart MW. Let them eat lunch: the impact of universal free meals on student performance. 2020;39:376-410.

14. Singh AS, Saliasi E, van den Berg V, Uijtdewilligen L, de Groot RHM, Jolles J, et al. Effects of physical activity interventions on cognitive and academic performance in children and adolescents: a novel combination of a systematic review and recommendations from an expert panel. Br J Sports Med. 2019;53(10):640-47.

15. Chriqui JF, Leider J, Temkin D, Piekarz-Porter E, Schermbeck RM, Stuart-Cassel V. State laws matter when it comes to district policymaking relative to the Whole School, Whole Community, Whole Child Framework. J Sch Health. 2020;90:907-17.

16. Edge Research. Healthy schools research - phase II. RWJF. 2019. https://www.rwjf.org/en/library/research/2019/09/healthy-schools-research-phase--ii.html.

17. Schuler BR, Saksvig BI, Nduka J, Beckerman S, Jaspers L, Black MM, et al. Barriers and enablers to the implementation of school wellness policies: an economic perspective. Health Promot Pract. 2018;19(6):873-83.

18. Bayrakdar S, Guveli A. Inequalities in home learning and schools' provision of distance teaching during school closure of COVID-19 lockdown in the UK. ISER Working Paper Series. 2020. https://www.iser.essex.ac.uk/research/publications/ working-papers/iser/2020-09.pdf.

19. Jæger MM, Blaabæk EH. Inequality in learning opportunities during Covid-19: evidence from library takeout. Res Soc Stratif Mobil. 2020;68:100524. 
20. Masonbrink AR, Hurley E. Advocating for children during the COVID-19 school closures. Pediatrics. 2020. doi:10.1542/peds.2020-1440.

21. Friedman J, York H, Mokdad A, Gakidou E. US children 'learning online' during COVID-19 without the internet or a computer: visualizing the gradient by race/ethnicity and parental educational attainment. SocArXiv. 2020. doi:10.31235/osf.io/42trc.

22. Drzensky F, Egold N, van Dick R. Ready for a change? A longitudinal study of antecedents, consequences and contingencies of readiness for change. J Change Manag. 2012;12(1):95-111.

23. Greenhalgh T, Robert G, Macfarlane F, Bate P, Kyriakidou O. Diffusion of innovations in service organizations: systematic review and recommendations. Milbank Q. 2004;82(4):581-629.

24. Hall GE, Hord SM. Implementing change: patterns, principles, and potholes. 2nd ed. Boston: Allyn and Bacon; 2006.

25. Oterkiil C, Ertesvåg SK. Schools' readiness and capacity to improve matter. Educ Inq. 2012;3(1):7192.

26. Weiner BJ. A theory of organizational readiness for change. Implement Sci. 2009;4(1):67.

27. Scaccia JP, Cook BS, Lamont A, Wandersman A, Castellow J, Katz J, et al. A practical implementation science heuristic for organizational readiness: $R=M C^{2}$.

28. J Community Psychol. 2015;43(4):484-501.

29. Teddlie C, Tashakkori A. A general typology of research designs featuring mixed methods. Res Sch. 2006;13(1):12-28.

30. Miles MB, Huberman AM, Saldana J. Qualitative data analysis: a methods sourcebook. Thousand Oaks: SAGE Publications Inc; 2020.

31. Saldana J, Omasta M. Qualitative research: analyzing life. Thousand Oaks: SAGE Publications Inc; 2018.

32. US Department of Health and Human Services. Qualitative methods in implementation science. National Institutes of Health. Bethesda, MD, USA: National Cancer Institute. 2018:1-31.

33. Sandelowski M. Whatever happened to qualitative description? Res Nurs Health. 2000;23(4):334-40.

34. Connolly K, Babbin M, Schwartz M. Feeding Connecticut children during COVID-19: stories of dedication. innovation, and collaboration from the field. UConn Rudd Center. 2020. https://portal.ct.gov/-/media/SDE/Nutrition/COVID-19/ Feeding_ CT_ Children_during_COVID19_Rudd_Report.pdf.

35. Nathan N, Wiggers J, Wyse R, Williams CM, Sutherland R, Yoong SL, et al. Factors associated with the implementation of a vegetable and fruit program in a population of Australian elementary schools. Health Educ Res. 2017;32(2):197-205.

36. Hudson KG, Lawton R, Hugh-Jones S. Factors affecting the implementation of a whole school mindfulness program: a qualitative study using the consolidated framework for implementation research. BMC Health Serv Res. 2020;20(1):133. 
37. Centeio EE. The have and have nots: an ever-present digital divide. J Phys Educ Recreat Dance. 2017;88(6):11-2.

38. Correia A-P. Healing the digital divide during the COVID-19 pandemic. Q Rev Distance Educ. 2020;21(1):13-21.

39. Lau EY, Wandersman AH, Pate RR. Factors influencing implementation of youth physical activity interventions: an expert perspective. Transl J Am Coll Sports Med. 2016;1(7):60-70.

40. Moore JB, Carson RL, Webster CA, Singletary CR, Castelli DM, Pate RR, et al. The application of an implementation science framework to comprehensive school physical activity programs: be a champion! Front Public Health. 2018;5:354.

41. Carlson JA, Engelberg JK, Cain KL, Conway TL, Geremia C, Bonilla E, et al. Contextual factors related to implementation of classroom physical activity breaks. Transl Behav Med. 2017;7(3):581-92.

42. McLoughlin GM, Candal P, Vazou S, Lee JA, Dzewaltowski DA, Rosenkranz RR, et al. Evaluating the implementation of the SWITCH® School Wellness Intervention through mixed methods. Under Review. 2020. doi:10.21203/rs.3.rs-40902/v1.

43. Swindle T, Johnson SL, Davenport K, Whiteside-Mansell L, Thirunavukarasu T, Sadasavin G, et al. A mixed-methods exploration of barriers and facilitators to evidence-based practices for obesity prevention in Head Start. J Nutr Educ Behav. 2019;1(9):1067-79.e1. 51 ).

44. Asada Y, Mitric S, Chriqui JF. Addressing equity in rural schools: Opportunities and challenges for school meal standards implementation. J Sch Health. 2020;90(10):779-86.

45. Haynes-Maslow L, Osborne I, Jilcott Pitts SB. Best practices and innovative solutions to overcome barriers to delivering policy, systems and environmental changes in rural communities. Nutrients. 2018;10(8).

46. Song SY, Wang C, Espelage DL, Fenning P, Jimerson SR. COVID-19 and school psychology: adaptations and new directions for the field. Sch Psychol Rev. 2020;49(4):431-7.

47. Carroll P, Dinh J, Lane H, McGuirt J, Zafari Z, Wang Y, et al. Evaluation of COVID-19 school meals response: Spring 2020. 2020.

http://www.marylandschoolwellness.org/media/SOM/Departments/Pediatrics/Maryland-SchoolWellness/Documents/School-Meal-Evaluation-Report_01_07_21_FINAL-FINAL.pdf.

48. Winthrop EV and R. Beyond reopening schools: How education can emerge stronger than before COVID-19. Brookings. 2020. https://www.brookings.edu/research/beyond-reopening-schools-howeducation-can-emerge-stronger-than-before-covid-19/ (Accessed 17 Jan 2021).

49. National. Academies of Sciences, Engineering, and Medicine. Communities in Action: Pathways to Health Equity. Washington, DC: National Academies Press.

50. Braveman P, Arkin E, Orleans T, Proctor D, Plough A. What Is Health Equity? And What Difference Does a Definition Make? Robert Wood Johnson Foundation. 2017. https://www.rwjf.org/en/library/research/2017/05/what-is-health-equity-.html.

51. Wandersman Center: Defining readiness. 2020. https://www.wandersmancenter.org/definingreadiness.html (Accessed 19 Nov 2020). 
52. Walker TJ, Brandt HM, Wandersman A, Scaccia J, Lamont A, Workman L, et al. Development of a comprehensive measure of organizational readiness (motivation $\times$ capacity) for implementation: a study protocol. Implement Sci Commun. 2020;1(1):103.

53. McLoughlin GM, McCarthy JA, McGuirt JT, Singleton CR, Dunn CG, Gadhoke P. Addressing food insecurity through a health equity lens: a case study of large urban school districts during the COVID19 pandemic. J Urban Health. 2020;97(6):759-75.

\section{Figures}

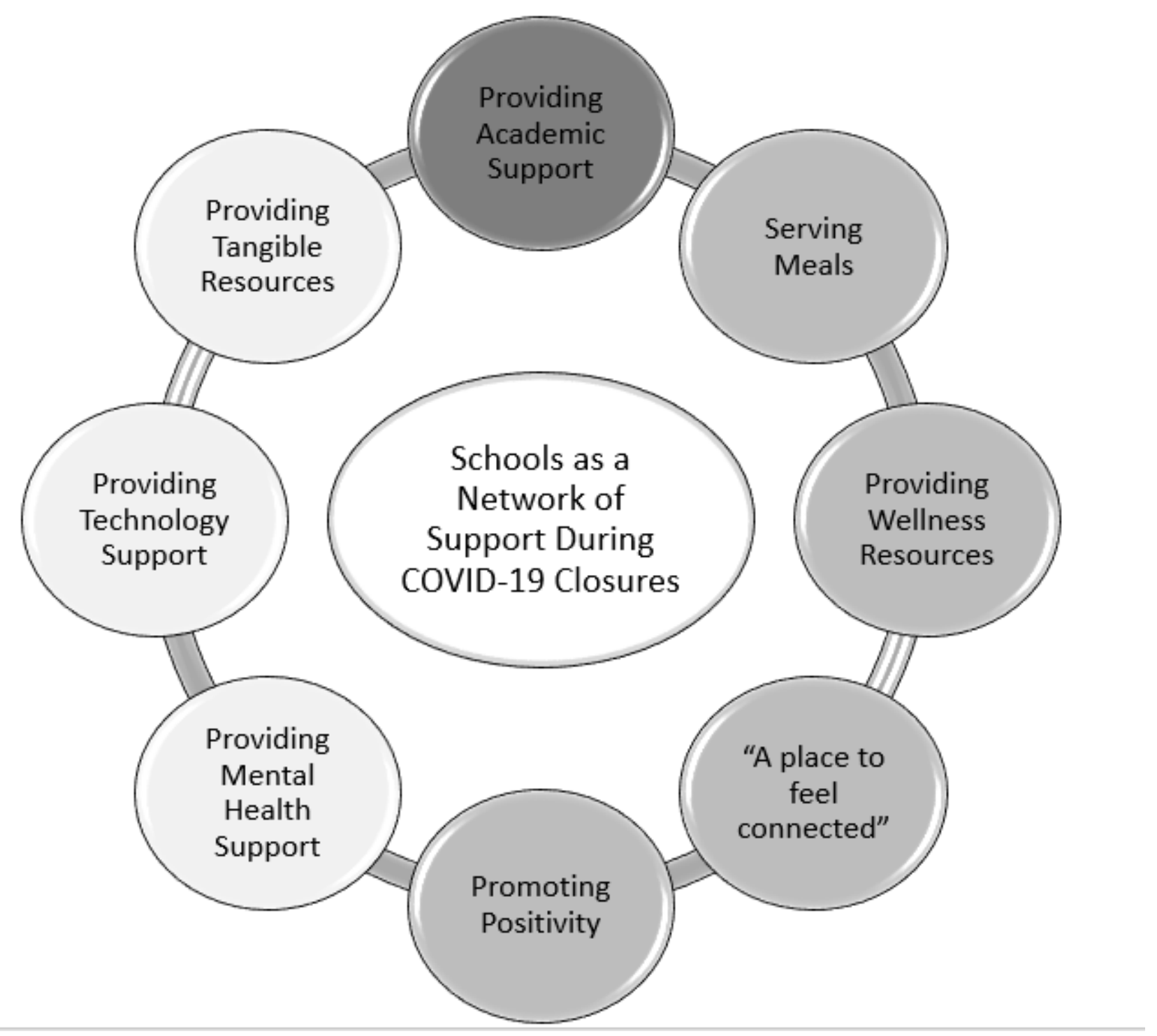

\section{Figure 1}

Components of Schools' Network of Support

\section{Supplementary Files}


This is a list of supplementary files associated with this preprint. Click to download.

- AdditionalFile1.docx

- AdditionalFile2.docx

- SRQRChecklistSUBMIT.docx 